\title{
Astronomy's own cloud
}

Meteorology and astronomy, two areas which seem to boil over periodically and publicly, have been placed under inquiry by the Australian Department of Science. Both committees of inquiry have been under way since late last year and were charged with reporting to the Minister for Science, Senator James Webster.

Neither report has been completed nor been made public. Some anxiety on this point is evident. The Secretary of the Department of Science, Sir Hugh Ennor, has only a few months left before retirement and, being the forceful character that he is, he doubtless wants to wrap up his work with the weather and star men safely settled for a while.

Relations between the Australian Bureau of Meteorology, headquartered in Melbourne, and the Canberra-based Department of Science have been tense ever since the bureau was transferred to the Department's responsibility under the Labor government. The committee was set up following regular and damaging leaks in the press of alleged confrontations between the bureau and the department. Its terms of reference included "making recommendations on the Head Office and Regional Organisational structure", but other terms cover all the bureau's functions.

The bureau has operated under its present act, the Meteorology Act, since 1955. The accompanying degree of independence was important to its Director, Dr Bill Gibbs, and to many users in this vast land mass where the rural industry and aviation services are peculiarly dependent on sound and comprehensive weather advice. The inquiry was seen by many as being the only method of resolving the bureaucratic conflicts. Significantly, the three-man committee did not include any professional meteorologist.

Things are a little different in astronomy. Ever since the early 1960 s when Australia leapt into the big league of astronomical nations with the building of the giant 64-metre radio dish at Parkes, New South Wales, a clamour for large facilities has been maintained, and to a reasonable extent satisfied. From the astronomer's point of view, their requests made good sense. Despite its relatively low terrain, Australia provided the only geologically and politically stable platform in the southern hemisphere for observing stars obscured to northern telescopes.

To a certain extent the argument of uniqueness is no longer as strong following the construction of some large telescopes in the South American Andes and Hawaii-at which stage other arguments take over, about maintaining a world lead, keeping the best scientists at home, and the prestigious PR that a nation gets from big telescopes. To back these arguments, the Australians now have a magnificently timed and very visible example of how astronomical research can lead to necessary (and profitable) application on Earth. At the end of March the Australiandeveloped 'Interscan' system for aircraft landing control in three dimensions was officially adopted as the next international standard. Interscan beat all comers from the USA, the USSR, Britain and Europe and is now the basis of a burgeoning industry. The microwave system was developed by the radioastronomers of the CSIRO Division of Radiophysics.

The Parkes facility was expanded in the mid-1960s to become an interferometer, and the main dish has recently been refigured at its centre to accept millimetre wavelengths. Among the other facilities around the country, the University of Sydney built its own radio interferometerthe so-called 'Mills Cross', named after its designer, Professor Bernard Mills-and an optical interferometer, Professor Robert Hanbury Brown's Stellar interferometer at Narrabri in northern New South Wales (now at the end of its useful life). CSIRO's Division of Radiophysics opened a magnificent solar observatory at Culgora, also in northern NSW, with Dr Paul Wild's Radioheliograph, together with optical solar telescopes of another division. Meanwhile, the Australian National University was expanding its optical observatory at Siding Spring in northern NSW, and in 1974 the joint Anglo-Australian Telescope Board opened its 3.9-metre telescope on the same mountain, then the largest optical telescope in the southern hemisphere. Beside it, the British also now operate a 1.9-metre Schmidt sky camera.

Enough for a nation of nearly 14 million people and few astronomers? Not so, said the astronomers, and asked for more-here remains our one chance of maintaining acrossthe-board, world-class excellence in a branch of science. Because of the sums involved for new facilities of significance, leading astronomers the world over have had to become politicians, and the Australians are no dullards at this game. Every minister responsible for science in Australia has eventually cried for mercy-continuance of the ad hoc lump-sum handouts of earlier days could no longer be justified, they said, without the unanimous recommendation of an expert committee.

And so began an unceasing stream of references from ministers to committees which either never reached unanimity or had to be replaced because of political change. The latest act has been the establishment of yet another committee to end all committees, this one by Senator James Webster.

The committee, it was announced, was to be "an interdepartmental committee (IDC) chaired by the Department of Science. The Committee comprises representatives of the Public Service Board and the Departments of Education, Science and the Treasury". The IDC (of non-astronomers, it will be noted) was charged with inquiring into the range of astronomical research and facilities.

The public servants of the IDC would clearly be responsible for making the recommendations to the minister. However, an "expert subcommittee" was named to assist the IDC. And there was the rub, as far as the scientific community was concerned. For, while the names of the sub-committee were publicised (it is chaired by Professor Kevin Westfold of Monash University), the IDC remained anonymous in the official announcement.

The gentle inquirer, however, would soon be told that the IDC was chaired by the redoubtable Sir Hugh Ennor, and included the wellregarded Secretary of the Department of Education, Mr Ken Jones, and some named but lesser fry. Yet the very possibility of some private shenanigans continued to worry some participators. The influential Academy of Science is understood to have initially refused to make a submission over the Academy's name.

As far as the astronomical politicians were concerned, an IDC was quite clearly a most inappropriate vehicle for assessing their aspirations. For the government, however, it has kept the lid on some vocal people for a while. Yet the government has let itself in for at least one more round by announcing that the IDC's report (intended for the Minister for Science) would be referred to ASTEC "for comment". And ASTEC reports to the Prime Minister, who is charged in most cases, and certainly including this one, with releasing their reports.

Peter Pockley 